University of Massachusetts Amherst ScholarWorks@UMass Amherst

1994

\title{
Diode-Laser-Based Detector for Doublet Peak Measurements in Flow Injection Analysis
}

\author{
Mary K. Carroll \\ University of Massachusetts Amherst \\ Julian Tyson \\ University of Massachusetts Amherst
}

Follow this and additional works at: https://scholarworks.umass.edu/chem_faculty_pubs

Part of the Chemistry Commons

\section{Recommended Citation}

Carroll, Mary K. and Tyson, Julian, "Diode-Laser-Based Detector for Doublet Peak Measurements in Flow Injection Analysis" (1994). Applied Spectroscopy. 1424.

Retrieved from https://scholarworks.umass.edu/chem_faculty_pubs/1424 


\section{Diode-Laser-Based Detector for Doublet Peak Measurements in Flow Injection Analysis}

\author{
MARY K. CARROLL* and \\ JULIAN F. TYSON†
}

Department of Chemistry, University of Massachusetts at Amherst, Amherst, Massachusetts 01003

Index Headings: Laser diode; Detector design; Flow injection analysis; Doublet peaks.

\section{INTRODUCTION}

Double peaks may be obtained in a single-line flow injection manifold if, by the time the reaction zone reaches the detector, there has been insufficient interspersion of the sample and reagent so that the sample is in excess over the reagent in the center of the reaction zone. The time between the peaks $(\Delta t)$ in a doublet profile in flow injection analysis (FIA) can be related to other experimental parameters by the equation

$$
\Delta t=(V / Q) \ln \left\{C^{\mathrm{s}}\left[\exp \left(V_{\mathrm{i}} / V\right)-1\right] / C^{\mathrm{R}}\right\}
$$

for the "well-stirred tank" model.1,2 Variation of the volume of the mixing chamber, $V$, the flow rate, $Q$, the injected volume of sample, $V_{\mathrm{i}}$, the concentration of sample injected, $C$, or the reagent concentration in the carrier stream, $C^{\mathrm{R}}$, affects the experimental value of $\Delta t$. The advantage of doublet peak measurements is the extension of the linear working range to higher values of concentration. If $V, Q, V_{\mathrm{i}}$, and $C^{\mathrm{R}}$ are chosen appropriately, the product profile will be a doublet with $\Delta t$ proportional to $\ln \left(C^{5}\right)$ over a large range of analyte concentration. ${ }^{2}$

Considerable work in the area of solid-state detectors for FIA has been performed, often with the use of lightemitting diodes (LEDs) as the source elements. ${ }^{3,4} \mathrm{~A}$ thorough review of LED-based detectors has been published recently. ${ }^{4}$ Patonay et al. investigated the application of near-infrared diode lasers for monitoring. ${ }^{5}$ Circuitry for pulse-width measurements ${ }^{6}$ and a pulse-width-based

\footnotetext{
Received 14 July 1993; revision received 8 November 1993.

* Present address: Department of Chemistry, Union College, Schenectady, NY 12308.

$\dagger$ Author to whom correspondence should be sent.
}

measurement system for the on-line, reverse FIA method of molybdenum blue reaction have been reported. ${ }^{7}$ Timebased measurements, such as peak widths or the time between doublets, are less subject to the problems of longterm baseline drift that can plague peak-height-based measurements. Additionally, the need for the instrument response to have a linear relationship to sample concentration (in this case, Beer's law) is obviated. The time between peaks in FIA is often on the order of seconds to minutes, and can be measured easily. Consequently, detectors for time-based measurements can be made with relatively inexpensive components and simpler designs than conventional detectors.

Here, we report a transmission detector for doublet peak measurements, which has as its light source a redemitting diode laser, and show the application of this detector to the determinations of hydroxide and phosphate ions. The change in transmittance of the indicator bromothymol blue was employed to monitor the on-line reaction between $\mathrm{HCl}$ in the carrier stream, and samples containing $\mathrm{NaOH}$. Phosphate was reacted on-line with ammonium molybdate and ascorbic acid to form molybdenum blue, which absorbs strongly in the red region of the electromagnetic spectrum. The detector is constructed of inexpensive yet rugged components, which renders its attractive for use in teaching laboratories and classroom demonstrations, and for application to process stream monitoring.

\section{EXPERIMENTAL}

All solutions were prepared with the use of deionized, distilled water as the solvent. For the determination of $\mathrm{OH}^{-}$, the carrier stream was $1.0 \times 10^{-5} \mathrm{M} \mathrm{HCl}$ and 6.0 $\times 10^{-6} \mathrm{M}$ bromothymol blue (BTB). Sodium hydroxide solutions were prepared by dilution of a $0.5 \mathrm{M}$ stock solution. For the molybdenum blue reaction, carrier stream A contained $2.00 \times 10^{-3} \mathrm{M}$ molybdate, prepared from ammonium molybdate and adjusted to $\mathrm{pH} 2.00$ with $\mathrm{HCl}$; carrier stream $\mathbf{B}$ was $0.16 \%$ ascorbic acid and $1 \%$ glycerine. Samples of various concentrations of ammonium phosphate were prepared by dilution of a 1000ppm stock solution ( $\mathrm{pH} 2.27)$ with $\mathrm{pH} 2.27 \mathrm{HCl}$. The $\mathrm{pH}$-adjustment of carrier solution $\mathbf{A}$ was performed so that the mixture of the two carrier streams would have $\mathrm{pH} 2.27$, the $\mathrm{pH}$ of the solutions of phosphate. This was done to avoid kinetic effects observed when solutions were not $\mathrm{pH}$-matched, resulting in a reversal in the relative peak heights of the doublets and variation in $\Delta t$ not predicted by theory. 


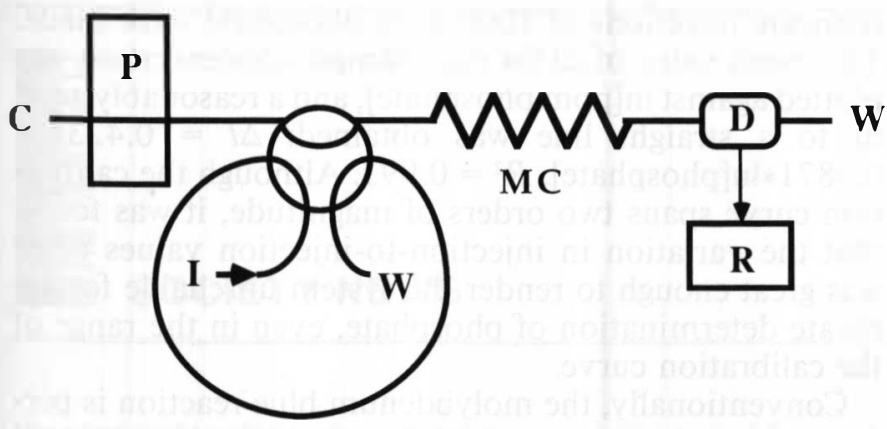

Fig. 1. Single-line manifold used for on-line determination of $\mathrm{OH}^{-}$ $\mathbf{C}$ is the carrier stream, containing $\mathrm{HCl}$ and BTB; $\mathbf{P}$ represents the pump. $\mathbf{V}$ is the six-port rotary injection valve; I indicates the sample injection position. $\mathbf{W}$ is waste. $\mathbf{M C}$ represents the mixing components (in this case coiled flow tubing). $\mathbf{D}$ is the detector, and $\mathbf{R}$ the recorder.

Figure 1 indicates the design of the simple single-line manifold used for the $\mathrm{BTB} / \mathrm{HCl}$ experiments. Teflon ${ }^{\circledR}$ flow tubing of $0.9-\mathrm{mm}$ inner diameter (Chemplast Inc., Chemfluor ${ }^{\circledR}$ tubing) was used for the manifold segments. The mixing component (MC) used was a coiled $600-\mathrm{mm}$ segment of the flow tubing (horizontal orientation coil, approximately $25 \mathrm{~mm}$ in diameter) and, as such, was not a conventional well-stirred mixing chamber. Varying sample loop volume and mixing component volume was accomplished by interchanging different lengths of flow tubing. Sample volumes are noted for relevant data. A Rheodyne six-port injection valve, $\mathbf{V}$, was switched manually from "fill" to "inject" (I) positions. Flow rates were varied by adjusting the speed of the variable-speed peristaltic pump (P, Ismatec sa, Cole-Parmer).

The double-line manifold used for the molybdenum blue reaction is diagrammed in Fig. 2. It was necessary to mix the ascorbic acid (carrier $\mathbf{B}$ ) and the ammonium molybdate (carrier A) solutions on-line prior to injection to avoid the red-absorbing product of the reaction that occurs if the two reagents are allowed to remain in contact with each other for a prolonged period of time (i.e., in the same carrier stream). An additional mixing component (MC) was placed between the confluence point of the two carrier streams and the point of injection of sample, in order to ensure that mixing of the molybdate and ascorbic acid solutions was complete before the phosphate sample was introduced into the mixture.

Detector Design. Figure 3 is a diagram of the detector. The source used was a 670-nm laser diode (Power Technology, Inc.); the laser module includes collimating/focusing optics and electronics, including a feedback loop for power stability. The laser module was powered by a

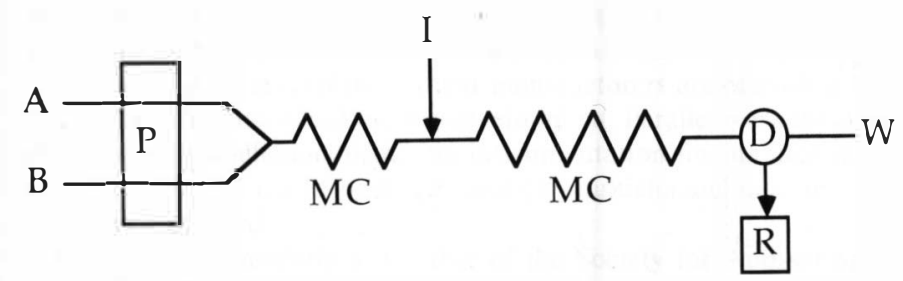

FIG. 2. Double-line flow injection manifold used for the molybdenum blue on-line reaction. Notation is the same as for Fig. 1, except that the two carrier streams, indicated by $\mathbf{A}$ and $\mathbf{B}$, intersect at a confluence point and pass through an additional mixing component (MC) prior to the point at which the sample is introduced to the stream.

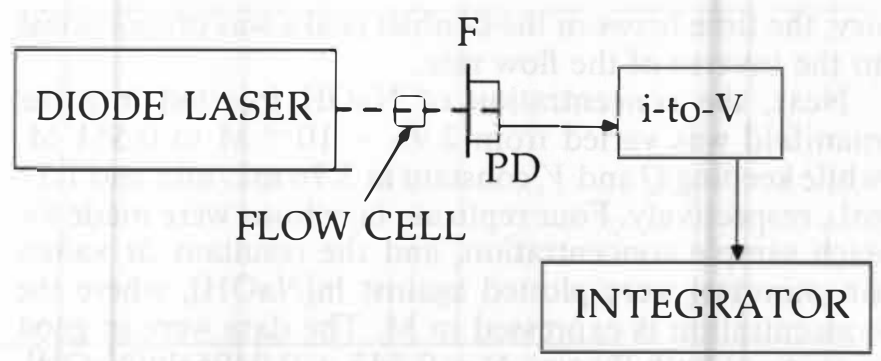

Fig. 3. Laser-diode-based transmittance detector design. $\mathbf{F}$ indicates a color filter; PD is the photodiode detector element; and i-to-V is the current-to-voltage converter.

6-V battery (Eveready); no attempt was made to control the temperature of the laser. The detector element was a PIN photodiode (Newark Electronics). A piece of squarecross-section capillary tubing (Wale Apparatus) was used as the flow cell; it was connected to the flow tubing by short segments of pump tubing, and the connections were made leak-proof with silicone sealant. The flow cell and photodiode (PD) were mounted in LEGO $^{\circledR}$ blocks; the laser diode mount was built in-house.

The flow cell has a pathlength of approximately $1 \mathrm{~mm}$, and a sampled volume of approximately $3 \mu \mathrm{L}$. The diode laser was focused to a point beyond the PD such that the entire active area of the PD was filled. This approach resulted in a slight variation in pathlength across the cell.

A color filter (moss green filter \#89, Edmund Scientific) was placed between the sample cell and the PD to attenuate the beam. (Attenuation of the beam prior to the flow cell would serve the same purpose.) If a detector were placed at a location on the cell at an angle of $90^{\circ}$ from the incident face, in order to collect fluorescence or scattered light, this filter would not be necessary. It was unnecessary to shield the detector further from room light, since the background produced by stray light was found to be insignificant.

The signal from the photodiode was sent through a current-to-voltage converter and amplifier. The signal voltage was offset to a positive value and then sent to an integrator (Hewlett-Packard Model HP 3394A) for data presentation. The integrator labeled each peak; values of $\Delta t$ were calculated manually. Circuitry necessary to operate the photodiode and to manipulate the signal into a form acceptable to the integrator was constructed in-house and has been described in an earlier paper. ${ }^{8}$

\section{RESULTS AND DISCUSSION}

Well-resolved doublet peaks were observed for both of the reactions. The molybdenum blue reaction was much more sensitive to slight variations in experimental procedure than was the acid-base reaction with BTB indicator.

Acid-Base Reaction. Two experiments to test the applicability of Eq. 1 to the manifold and detector were performed. First, flow rates were varied from 1.29 to 4.99 $\mathrm{mL} / \mathrm{min}$, while sample volume was fixed at $1.37 \mathrm{~mL}$ and sample $\mathrm{OH}^{-}$concentration held at $4.07 \times 10^{-3} \mathrm{M}$. A plot of $\Delta t$ in minutes vs. $1 / Q$ in $\mathrm{min} / \mathrm{mL}$ for all data points (performed with CricketGraph software) resulted in a good fit to a straight line: $\Delta t=5.69 \times 10^{-2}+2.08(1 / Q), R^{2}$ $=0.998$. This result indicates good agreement with the- 
ory; the time between the doublet peaks was proportional to the inverse of the flow rate.

Next, the concentration of $\mathrm{NaOH}$ injected into the manifold was varied from $2.95 \times 10^{-4} \mathrm{M}$ to $0.551 \mathrm{M}$, while keeping $Q$ and $V_{\mathrm{i}}$ constant at $3.76 \mathrm{~mL} / \mathrm{min}$ and 1.37 $\mathrm{mL}$, respectively. Four replicate injections were made for each sample concentration, and the resultant $\Delta t$ values (in minutes) were plotted against $\ln [\mathrm{NaOH}]$, where the concentration is expressed in $\mathrm{M}$. The data were in good agreement with theory: $\Delta t=0.843+0.0496 * \ln [\mathrm{NaOH}]$, $R^{2}=0.992$. The working range of the system spanned four orders of magnitude.

The detection limit is fixed by the minimum peak separation (approximately $10 \mathrm{~s}$ ) that can be accurately recorded by the integrator. (Of course, the detection limit is also a function of noise sources in the system and of the particular chemical reaction; a detailed analysis of the precision of the double peak procedure is in progress. ${ }^{9}$ ) For the aforementioned reaction and conditions, the detection limit was $10^{-6} \mathrm{M}$. It should be noted that varying the concentration of $\mathrm{HCl}$ in the carrier stream would change the observed detection limit.

The extent to which the tubing was coiled had no effect on the plot of $\Delta t$ vs. $1 / Q$; however, for less tightly coiled tubing (coil diameter approximately $40 \mathrm{~mm}$ ), the plot of $\Delta t$ vs. $\ln \left[\mathrm{OH}^{-}\right]$was not a straight line but a smooth curve. (Loosely coiled tubing does not act as a "well-stirred tank"; similar deviations have been noted previously, ${ }^{8}$ and a thorough comparison of a variety of types of mixing components has been performed. ${ }^{10}$ ) These curves were less convenient to use than straight-line calibration plots; nevertheless, they could be used for unknown determinations. Solutions containing $6.6 \times 10^{-3}$ and $6.6 \times 10^{-4}$ $\mathrm{M}$ hydroxide were prepared and analyzed. On the basis of the $\Delta t$ values measured, the solutions were determined to be $6.2 \times 10^{-3}$ and $6.7 \times 10^{-4} \mathrm{M}$ hydroxide, corresponding to an observed error of $6 \%$ and $1 \%$, respectively.

Molybdenum Blue Reaction. In general, the run-to-run reproducibility of the $\Delta t$ measurements was poorer than that found in the acid-base study, and is most likely due to suboptimal reaction conditions. Measured values of $\Delta t$ varied substantially for the lower concentrations used $(2.5$ and $5.0 \mathrm{ppm}$ ), and these data were not included in the calibration curve. Five replicate injections of each of six phosphate concentrations from 10 to $500 \mathrm{ppm}$ and three replicate injections of 1000 ppm phosphate were made. The mean value of $\Delta t$ for each sample concentration was plotted against $\ln$ [ppm phosphate], and a reasonably good fit to a straight line was obtained: $\Delta t=0.423+$ $0.0871 * \ln \left[\right.$ phosphate], $R^{2}=0.993$. Although the calibration curve spans two orders of magnitude, it was found that the variation in injection-to-injection values of $\Delta t$ was great enough to render the system unreliable for accurate determination of phosphate, even in the range of the calibration curve.

Conventionally, the molybdenum blue reaction is performed in a boiling water bath and is labor-intensive. ${ }^{11}$ Here, room-temperature solutions were used, and the analysis time was less than $5 \mathrm{~min}$. As a result, the reaction was incomplete by the time the sample bolus reached the detector, and small variations in equivalence points might have occurred from run to run. One would expect these variations to be most pronounced in the samples containing low-concentration phosphate solutions. This would explain the results observed. Use of a proper mixing chamber or knotted tubing might result in improved reproducibility of the $\Delta t$ measurements, as would optimization of the on-line reaction (variation of $\mathrm{pH}$, for example).

\section{ACKNOWLEDGMENTS}

We thank Mike Conboy of Instrumentation Support in the Department of Chemistry at the University of Massachusetts at Amherst for the construction of the controller unit used in these experiments.

1. J. F. Tyson, Anal. Chim. Acta 179, 131 (1986).

2. J. F. Tyson, Analyst 112, 523 (1987).

3. M. Trojanowicz, P. J. Worsfold, and J. R. Clinch, Trends Anal. Chem. 7, 301 (1988).

4. P. K. Dasgupta, H. S. Bellamy, H. Liu, J. L. Lopez, E. L. Loree, K. Morris, K. Petersen, and K. A. Mir, Talanta 40, 53 (1993).

5. G. Patonay, J. M. Zen, and T. Czuppon, Proc. SPIE-Int. Soc. Opt. Eng. 1637, 142 (1992).

6. P. K. Dasgupta and E. L. Loree, Anal. Chem. 58, 507 (1986).

7. P. J. Worsfold, J. R. Clinch, and H. Casey, Anal. Chim. Acta 197, 43 (1987).

8. M. K. Carroll and J. F. Tyson, J. Chem. Educ. 70, A210 (1993).

9. R. T. Echols and J. F. Tyson, unpublished results.

10. R. T. Echols and J. F. Tyson, Anal. Chim. Acta, in press.

11. A. I. Vogel, Textbook of Quantitative Inorganic Analysis (Longman, London and New York, 1978), 4th ed., p. 756. 